\title{
Relevância Processual da Reforma Penal (*)
}

\author{
Rogério Lauria Tucci \\ Professor Adjunto do Departamento de Direito \\ Processual da Faculdade de Direito da Univer- \\ sidade de São Paulo e Membro das Comissões \\ elaboradora e revisora do Anteprojeto de C6. \\ digo de Processo Penal.
}

\begin{abstract}
SUMARIO: I PROLEGOMENOS: 1. Considerações preambulares - 2. Orientacão dos trabalhos de elaboração legislativa - 3. Principais inovações introduzidas - II ANALISE DAS INOVAC̄óES PROJETADAS: 4. Simplificacão dos procedimentos: a) Generalidades; b) Procedimento sumarissimo; c) órgão colegiado de primeira instancia; d) Aditamento da denúncia - 5. Procedimento recursal - 6. Utilizacão de gravação sonora ou equivalente - 7. Medidas alternativas à prisão provisoria 8. Reprimenda a criminalidade violenta - 9. Procedimento nas causas de competência do Tribunat do Júri - 10. Exame criminológico - 11. Posicionomento dos sujeitos do processo penal - 12. Regulamentação mais expressiva do habeas corpus - III CONCLUSÃO: 13. Derradeinas observacões.
\end{abstract}

\section{I - PROLEGÔMENOS}

\section{Considerações preambulares}

Antes de iniciar a exposição do tema que devo abordar - RELEVANCIA PROCESSUAL DA REFORMA PENAL —, desejo expressar minha grande satisfação e correlato reconhecimento pela designação como Coordenador e Conferencista deste "I Ciclo de Estudos sobre Direito e Processo Penal (Reforma Penal)", idealizado pelo caro amigo LAERCIO DA COSTA PELLEGRINO, ilustre e atuante Presidente deste prestigioso Instituto dos Advogados Brasileiros.

Assim também as generosas palavras de saudação com que fui cumulado, nesta oportunidade.

Isso expresso, no trato da matéria em referência deve ter-se presente, de logo, a necessidade de perquirição da importância das modjficações alvitradas relativamente ao processo penal, no âmbito da Reforma projetada.

(*) Conferência no "I Ciclo de Estudos sobre Direito e Processo Penal (Reforma Penal)", do Instituto dos Advogados Brasileiros, em 7 de abril de 1983. 
Ao objetivá-la, é com real alegria e orgulho que, como membro das Comissões elaboradora e revisora do Anteprojeto de Código de Processo Penal (agora Projeto prestes a ser enviado ao Congresso Nacional pelo Excelentíssimo Senhor Presidente da República), a afirmo manifesta.

Tal afirmação, aliás, quer no tempo, quer no espaço, não constitui novidade.

$\mathrm{Na}$ aguda observação de JOÃO MENDES DE ALMEIDA JÚNIOR, O processo criminal brasileiro, $4^{\text {a }}$ ed., Rio de Janeiro de 1959, vol. I, pág. $13, \mathrm{n}^{\circ} 3$, sintetizando o entendimento corrente na doutrina processual penal universal,

"As leis do processo são o complemento necessário das leis constitucionais; as formalidades do processo são as atualidades das garantias constitucionais. Se o modo e a forma da realização dessas garantias fossem deixadas ao critério das partes ou à discrição dos juízes, a justiça, marchando sem guia, mesmo sob o mais prudente dos arbítrios, seria uma ocasião constante de desconfianças e surpresas. É essa a razão pela qual, se os legisladores puderam, em algumas épocas, deixar as penas ao arbítrio dos juízes, nunca deixaram ao mesmo arbítrio as formalidades de suas decisões".

Daí, por um lado, a indispensabilidade de grande prudência nos respectivos trabalhos de elaboração legislativa. Até porque, no dizer de M. FAUSTIN HÉLIE, Traité de l'instruction criminèlle, Bruxelas, 1863, ed. aumentada por J. S. G. Nypel e M. Léopold Hanssens, tomo I, pág. $2, \mathrm{n}^{\circ} 1$, com a atenção voltada para o estudo do processo penal, se a ação judiciária apresentar-se embaraçada por excessivas precauções e formas complicadas, ou, pelo contrário, com regras concessivas de exagerada liberdade à atuação judicial, incompletas ou indefinidas, "a justiça deixará de ser justiça".

E, por outro, a imprescindibilidade, também, de que as leis processuais penais sejam, realmente, bem elaboradas, de sorte a propiciarem segura e integral investigação da verdade material em prol do justo resultado do processo, com a assecuração do ius libertatis do inocente e a inflição ao culpado da pena cominada ao crime ou contravenção cuja prática lhe é imputada.

\section{Orientação dos trabalhos de elaboração legislativa}

Essa, dúplice, foi, por certo, a preocupação dos integrantes, tanto da Comissão elaboradora, como da revisora, do Anteprojeto de Código de Processo Penal de 1981.

Tiveram elas em vista, sobretudo, a necessidade de agilização do procedimento penal, mediante a regulamentação de um sistema procedimental tecnicamente estruturado segundo a moderna ciência 
processual penal e os ditames da realidade brasileira, posta em território imenso no qual se colocam diversificadas situações de progresso, comunicação, ambiência e costumes.

Atreladas, outrossim, ao consenso universal da indole do processo penal como garante da liberdade jurídica do membro da comunhão social tido como indigitado autor de infração a preceito penal normativo, bem como da imprestabilidade atual da pena privativa de liberdade, exceto no tocante aos denominados prisioneiros residuais, procuraram minimizar os efeitos da instauração e complementação da persecutio criminis em relação aos indicados e acusados primários, de bons antecedentes e ocasionais.

Correlata e coerentemente, impuseram rigoroso tratamento aos delinqüentes perigosos, cuidando de coibir, tanto quanto possível, a criminalidade violenta que grassa em toda parte, especialmente nos grandes centros.

E, por outro lado, reforçando a conformação técnica e a utilização prática de institutos de grande relevância e expressividade, como o habeas corpus, a revisão criminal e a prisão provisória, procuraram simplificar, ao máximo, todos os tipos procedimentais estatuídos, de sorte a possibilitar a realidade de um processo penal como instrumento, que deve ser, de segura aplicação do Direito e de pronta realização de Justiça.

\section{Principais inovações introduzidas}

Tudo isso encontra-se, de certa forma, sintetizado na Apresentação com que o mencionado Anteprojeto de Código de Processo Penal foi submetido à apreciação da intelectualidade jurídica brasileira pelo Excelentíssimo Senhor Ministro de Estado da Justiça, IBRAHIM ABI-ACKEL.

Houve por bem, então, Sua Excelência, traduzindo com a reclamada fidelidade a orientação imprimida à fase inicial dos trabalhos de elaboração da projetada Codificação processual penal, enfatizar que, dentre "as inovações introduzidas nessa fase de atualização do Projeto" ( $\mathrm{n}^{\circ}$ 633, de 1975; retirado do Congresso Nacional pela Presidência da República, no Governo GEISEL), fazem por merecer destaque as seguintes:

“a) simplificação dos procedimentos, designadamente do recursal;

b) instituição de procedimento sumaríssimo, com dispensa de inquérito policial, para pronto julgamento das causas penais de menor importância e das referentes aos denominados delitos de trânsito;

c) introdução do uso de gravação sonora, ou meio equivalente, onde seja possível e conveniente; 
d) introdução de medidas alternativas à prisão provisória, de acordo com as recomendações da Organização das Nações Unidas (ONU), em recente Congresso, realizado em Caracas, sobre Prevenção do Crime e Tratamento do Delinqüente;

e) criação de órgão colegiado de primeiro grau, para julgamento, em grau de recurso, das causas processadas em rito sumaríssimo, para desafogo dos trabalhos dos Tribunais;

f) simplificação do procedimento relativo aos processos de competência do Tribunal do Júri, particularmente no tocante à formulação de quesitos;

g) deslocação do exame criminológico para o Processo de Execução, como incidente deste;

h) fortalecimento do instituto da prisão preventiva com referência ao delinqüente perigoso, nos casos de crimes de roubo, latrocínio, extorsão, seqüestro, estupro, atentado violento ao pudor, rapto não consensual, quadrilha ou bando e tráfico de entorpecentes ou de substância que determine dependência física ou psíquica, a fim de melhor aparelhar a Justiça Penal para o combate à criminalidade violenta".

A elas podem ser acrescentadas, ainda, em enumeração que longe está de ser exaustiva, as respeitantes à determinação rigorosamente científica do posicionamento dos sujeitos processuais - agente do Poder Judiciário (juiz ou tribunal) e partes em sentido processual -, e aos contornos dos institutos do habeas corpus e da modalidade de prisão provisória denominada prisão temporária.

\section{II - ANÁLISE DAS INOVIAÇÕES PROJETADAS}

\section{Simplificação dos procedimentos}

\section{a) Generalidades}

Sendo manifestamente escasso o tempo de que disponho para a apreciação dessas novidades e reformulações, procurarei ater-me, neste ensejo, ao exame sucinto das mesmas.

Em primeiro lugar, seguindo, em linha de princípio, a ordem seqüencial supraestabelecida, devo abordar a propalada simplificação dos procedimentos.

À evidência que se cogita da simplificação dos procedimentos do processo de conhecimento, que se dividem, como é sabido e a própria regulamentação projetada estabelece, em comum e especiais. 
Estes, peculiarizados cada qual pelas características do Direito material que os reclamam, exigem uma série de normas específicas, implicativas de sua destinação exclusiva a determinado tipo de conflito de interesses submetido à apreciação do órgão jurisdicional.

Por isso que, devendo ser estatuídos em menor número possível, ficaram reduzidos a três - procedimento por crimes contra a propriedade imaterial, procedimento penal falimentar e procedimento relativo a causas da competência do Tribunal do Júri.

Aliás, especial por inteiro é, apenas, o último, de que falarei mais adiante (in número 9 , infra).

Os outros, nas ações penais referentes a crimes contra a propriedade imaterial ou falimentares, não obstante a especificação inicial, ainda quando da formação do processo assumem o rito ordinário ou sumário, igualando-se, portanto, ao comum.

Já o derradeiramente apontado - comum - subdivide-se em ordinário e sumário, espécie em que entra o sumaríssimo.

Contemplados os três, a adoção de cada um deles, como sempre aconteceu em nosso Direito, determina-se, em regra, pela qualidade e quantidade da sanção estabelecida para a infração penal que constitui objeto do processo.

Assim é que, tratando-se de contravenção, crime de ação penal pública a que cominada pena de detenção até um ano ou do denominado delito de trânsito, o procedimento cabente é o sumaríssimo; crime a que cominada pena de detenção superior a um ano ou de ação penal de iniciativa privada, o procedimento é o sumário; e crime a que cominada pena de reclusão, o procedimento é o ordinário (cujas regras se aplicam, subsidiariamente, aos outros).

Ademais, em qualquer procedimento do tipo comum reclama-se efetiva atuação defensiva do acusado, mediante resposta à acusação, precedendo a fase postulatória ao recebimento da denúncia ou da queixa - tudo com facilmente perceptível amplitude de defesa e de sorte a coarctar inútil prosseguimento do feito para a colheita de prova desnecessária.

É que, estatuído, a par do saneamento, o julgamento conforme o estado do processo, faculta-se ao juiz, por ocasião da fase saneadora, proferir julgamento segundo o estado dos autos (a que corresponde a extinção do processo sem julgamento do mérito) ou julgamento antecipado da causa penal (equivalente ao do meritum causae).

\section{b) Procedimento sumaríssimo}

Deve ser ressaltado, outrossim, que o procedimento sumarissimo, bem mais simplificado, como de mister, do que o sumário (cf. ADROALDO FURTADO FABRICIO, Doutrina e prática do procedimento sumaríssimo, Porto Alegre, 1977, pág. 23, nº 4: "O superlativo deve 
indicar o grau máximo de sumaridade formal"), constitui, induvidosamente, uma inovação deveras original.

Tem-se em vista, com a sua implantação, a realização de julgamento da causa em imediata seqüência à prática da infração penal.

Assim é que se dispensa, em casos que tais, a efetuação de inquérito, incumbindo à autoridade policial, apenas, registrar o fato (mediante, certamente, a lavratura de "Boletim de Ocorrência"), ordenar a realização de exames de corpo de delito e outros que se façam necessários, e encaminhar os papéis que os documentam ao juiz competente.

Essa apresentação deve ser feita imediatamente ao juiz em exercício nos denominados Juizados Especiais, onde tiverem sido instalados e com funcionamento previsto para até vinte e quatro horas diárias - inclusive em sábados, domingos e feriados -, ou no momento inicial do expediente do primeiro dia útil subseqüente, ao juiz de Vara Criminal da Comarca.

$\mathrm{E}$, ao ensejo, o órgão jurisdicional deve dar vista dos aludidos documentos ao Promotor Público oficiante, e também necessariamente presente, para: $a$ ) promover o arquivamento das peças de informação; b) solicitar a adoção do rito sumário, quando houver vários acusados, concurso de crimes, crime continuado ou a complexidade dos fatos exigir procedimento mais amplo (modificação, aliás, igualmente possivel, de procedimento sumário a ordinário); ou $c$ ) oferecer denúncia.

A acusação efetua-se, então, oralmente, reduzindo-a o escrivão a termo, do qual deve constar, também, a designação da audiência de instrução e julgamento dentro de, no máximo, dez dias, e a ordem de citação, que se concretiza com a entrega de cópia ao acusado.

A realização da audiência é inadiável, podendo ocorrer em qualquer das vinte e quatro horas do dia, nos Juizados Especiais, e no horário do expediente forense nos demais Juízos. E ao acusado, além da atuação defensiva, propriamente dita (por defensor constituído ou público), concede-se a possibilidade de aquiescência à acusação (instituto previsto para as infrações a que cominadas penas de multa, prisão simples ou detenção, correspondente ao pagamento de determinada quantia, uma só vez, em especificadas circunstâncias, e sem qualquer resquício no tocante à primariedade), que propicia a extinção do processo sem julgamento do mérito.

Isso não acontecendo, e recebida a acusação, procede-se à instrução e ao debate, não havendo lugar para a suspensão dos trabalhos, em hipótese alguma: a audiência deve terminar, sendo permitido, apenas, que, não se encontrando o juiz habilitado a proferir sentença, desde logo, a publique no prazo de cinco dias.

Exige-se, como visto, o máximo de concentração e oralidade, que tem como corolários óbvios, além daquela, o imediatismo e a identi- 
dade física do juiz, num procedimento oral por excelência (cf. JOSÉ FREDERICO MARQUES, Elementos de Direito Processual Penal, $2^{\text {a }}$ ed., Rio de Janeiro - São Paulo, 1965, vol. I, pág. 67, n’ 37; com lastro em doutrinação de LUIZ MACHADO GUIMARÃES e NICETO ALCALÄ-ZAMORA Y CASTILLO - RICARDO LEVENE).

\section{c) órgão colegiado de primeira instância}

Outra especial novidade da Reforma projetada, relativamente, ainda, às causas de procedimento sumaríssimo, é a instituição do denominado órgão colegiado de primeira instância.

Visando ao desafogo dos trabalhos dos órgãos jurisdicionais de segundo grau de jurisdição, a criação, onde possível e conveniente, de colegiado compentente para o julgamento dos recursos contra os atos decisórios proferidos pelo juiz singular (e, obviamente, pleitos e incidentes correlatos) presta-se, outrossim, à concretização do ideal de celeridade na prestação jurisdicional, que domina o processo moderno (cf., a respeito, meu Do julgamento conforme o estado do processo, $2^{\text {a }}$ ed., São Paulo, 1982, pág. 44, nº 20).

$\mathrm{E}$ tem-se em vista, com ela, como a denominação deixa entrever, a composição de corpo julgador por juízes de primeiro grau, em exercício nas Varas dos Juizados Especiais ou de Comarcas da mesma Circunscrição Judiciária nas quais estes não sejam instalados, para a reapreciação das mencionadas causas, havendo recurso, bem como para o exame de pedidos que lhes sejam conexos ou incidentais. recursos,

Como expressa o dispositivo que lhe diz respeito, e especificado aos

"Os processos de competência recursal de órgão colegiado de primeira instância continuarão, em sua tramitação, no juízo de origem, incumbindo ao escrivão encaminhar os autos ao órgão do Ministério Público oficiante no recurso e, sucessivamente, ao juiz que deva atuar como relator, de acordo com o disposto na legislação local de organização judiciária, que deve estabelecer, também, a composição, a direção e o funcionamento do órgão, bem como o local e o número de sessões de julgamento"

Fácil fica de perceber, de resto, mediante a simples leitura do texto transcrito, que à legislação local de organização judiciária é deixada a complementação da estrutura e da disciplina da atuação do órgão colegiado de primeira instância, cuja utilidade a prática forense encarregar-se-á de mostrar em não muito largo tempo.

\section{d) Aditamento da denúncic}

Referentemente, já agora, aos procedimentos ordinário e sumário, deve ser anotada inovação de acentuada relevância no tocante ao aditamento da denúncia. 
Estabelecida a regra genérica da ordenação procedimental, segundo a classificação legal do fato tido como infração penal, de sorte a fixar-se, de logo, o conteúdo da acusação, quando do proferimento do ato decisório de saneamento do processo, somente ao final da instrução torna-se possível aditar a denúncia.

É preciso lembrar, a tal propósito, que, no sistema procedimental projetado, ao sanear o processo, recebendo a proposição acusatória, o juiz deve designar data e hora para a realização da audiência de instrução e julgamento.

Nesta, única e una, há lugar para a produção de todas as provas faltantes, a saber: interrogatório do acusado, esclarecimentos dos peritos, declarações do ofendido, inquirição das testemunhas arroladas na acusação e na defesa, acareações, reconhecimento de pessoa e de coisa, e outras entendidas necessárias pelo juiz.

E, após finda a instrução, é dado ao Ministério Público pedir vista dos autos para aditar a denúncia, mediante termo imediatamente lavrado.

Essa providência, admitido que seja o aditamento da denúncia, implica a interrupção dos trabalhos da audiência, por tornar-se imprescindivel a oportunidade de complementação da atuação defensiva do acusado, inclusive com novo interrogatório e inquirição de outras testemunhaas que venham a ser arroladas, em subseqüente momento processual (v., a respeito, EDUARDO ESPINOLA FILHO, Código de Processo Penal Brasileiro anotado, $3^{\text {a }}$ ed., Rio de Janeiro, 1955, vol. IV, págs. 96 e segs., ñ 757 ).

Caso contrário, não havendo aditamento ou sendo ele rejeitado, prossegue-se na realização da audiência, com o debate e o julgamento ou, quando a causa apresentar questões complexas, de fato e de direito, com o deferimento a outra oportunidade da apresentação de alegações escritas e da pronunciação da sentença de mérito.

\section{Procedimento recursal}

Por outro lado, destaque particular deve ser dado à simplificação do procedimento recursal.

É que, em consonância com a exigência de atendimento à verificação dos pressupostos objetivos dos recursos em geral, se coloca diante dos trabalhos de reformulação legislativa a indispensabilidade de adequação da impugnativa ao ato decisório recorrível.

Ora, com técnica símile à do Código de Processo Civil em vigor, dos atos decisórios prescritos sentenças, decisões interlocutórias e despachos, - estes são irrecorriveis. $\mathrm{E}$, enquanto da sentença cabe apelaçấo, a decisão interlocutória desfavorável reclama agravo de instrumento para a sua revogação ou reforma. 
Reduzem-se, destarte, a dois os recursos admissíveis contra atos decisórios proferidos no procedimento em primeiro grau de jurisdição - o agravo de instrumento (aqui também, o propriamente dito e o retido) e a apelação. Até porque, não sendo, realmente, recurso os embargos de declaração encontram-se regulamentados, de acordo com a natureza jurídica que ostentam, como incidente de complementação de julgamento carente de clarificação (v. meu Curso de Direito Processual - Processo Civil de Conhecimento, II, São Paulo, 1976, págs. 333/334, no 1; e, no mesmo sentido, HÉLIO TORNAGHI, Curso de Processo Penal, São Paulo, 1980, vol. II, págs. 352/353).

Já num plano superior, três são os recursos cabíveis contra acórdãos de órgãos colegiados: embargos infringentes, recurso ordinário constitucional e recurso extraordinário.

Os embargos infringentes apresentam-se algo diferenciados dos previstos atualmente.

Sua admissibilidade restringe-se aos julgados não unânimes, em grau de apelação ou em revisão criminal.

Além disso, não mais são pertinentes, tão-só, ao acusado, podendo opô-los, também, o Ministério Público quando, por votação majoritária, o acórdão da apelação reformar a sentença condenatória, em benefício do acusado.

O recurso ordinário constitucional e o recurso extraordinário, cuja admissibilidade resulta de preceituações constitucionais, prestam-se, a seu turno, como é notório, para enfrentar, respectivamente, ato decisório denegatório de habeas corpus, proferido por tribunais federais. ou estaduais, e acórdão lavrado em única ou última instância pelos órgãos colegiados de segundo grau, nas circunstâncias estabelecidas no artigo 119, inciso III, da Constituição da República (com a redação da Emenda n 1 , de 17 de outubro de 1969).

A legislação projetada cuida, apenas, como de mister, da complementação legislativa dos preceitos constitucionais em que instituídos ambos os recursos, quanto ao processamento no juízo de origem, já que no Supremo Tribunal Federal o procedimento é regulamentado pelo seu regimento interno (cf., ainda, a Carta Magna do país, artigo 119, $\S 3^{\circ}$, letra $c$, com a redação da Emenda Constitucional $\mathrm{n}^{\circ} 7$, de 13 de abril de 1977; e, in genere, JOSÉ FREDERICO MARQUES, Elementos de Direito Processual Penal cit., vol. IV, págs. 316, n 1.133, e $324, \mathrm{n}^{\circ}$ 1.138).

\section{Utilização de gravação sonora ou equivalente}

Preocupado também, em diversificado aspecto, com a morosidade e o obsoletismo dos meios empregados, atualmente, na realização das audiências, em especial quanto à colheita da prova oral, o examinado 
lavor de elaboração legislativa introduz, onde possível e conveniente, a utilização do sistema de gravação sonora, ou equivalente.

Nesse caso, devem ser observadas as seguintes regras genéricas: a) transcrição, por escrito, do conteúdo da gravação deve ser juntada aos autos do processo, no prazo de cinco dias; b) nos cinco dias subseqüentes qualquer das partes pode requerer a conferência dessa transcrição com a gravação, em sua presença e no prazo máximo de quinze dias; c) a gravação deve ser conservada em cartório até o dia em que a sentença transitar em julgado; d) sendo esta proferida em audiência, o prazo para recorrer inicia-se na data da juntada da transcrição da gravação aos autos do processo; $e$ ) havendo retificação da transcrição, em virtude da conferência procedida, faculta-se ao requerente o aditamento das razões de recurso, no prazo de cinco dias.

Desnecessário torna-se, por certo, enfatizar as vantagens do uso dos modernos processos eletrônicos com a finalidade de agilizar, também, os trabalhos das audiências.

$\mathrm{E}$ isso, principalmente, quando se tenha presente a igualmente estatuída determinação de que as perguntas das partes e do assistente do Ministério Público sejam feitas, diretamente, ao inquirido, sob a fiscalização do juiz.

Coibida assim, aliás, qualquer prática abusiva do integrante do processo, colaborador da Justiça Penal e submisso, sempre, à supervisão do Magistrado dirigente do procedimento, fica por terra, concessa venia, a conhecida objeção de que os inquiridos venham a exprimir as palavras desejadas pelo inquiridor.

Além do que, longe de representarem resultado de atuação incorreta, os depoimentos gravados apresentam-se; inegavelmente, fiéis às informações prestadas pelo depoente, eis que expressas por suas próprias palavras (o que, como é notório, e infelizmente, muitas vezes não acontece na atualidade. ).

\section{y Medidas alternativas à prisão provisória}

No tocante ao também novidadoso poder de aplicação, pelo juiz, de medidas alternativas à prisão provisória, resulta ele, a exemplo do que acontece com a implantação de novo sistema de penas, especialmente as restritivas de direitos, na Parte Geral do Código Penal, das recomendações da Organização das Nações Unidas, em Congresso realizado em 1980 na cidade de Caracas, Venezuela, sobre "Prevenção do Crime e Tratamento do Delinqüente"

Como clarificado pelo eminente Professor FRANCISCO DE ASSIS TOLEDO, Coordenador da Reforma Penal, em excelente artigo publicado na Revista dos Tribunais, São Paulo, 1981, vol. 544, págs. 471 e seguintes, sob o título "Prevenção do crime e tratamento do delinqüente", dentre as medidas a serem empregadas no combate à crimi- 
nalidade coloca-se a "desinstitucionalização" do "sistema correcional" existente, assim explicada:

"Consiste ela na substituição da privação da liberdade, nas fases pré-judicial, judicial e pós-judicial, para todo acusado ou condenado que não esteja, por ausência de periculosidade, a exigir essa medida extrema, dispendiosa, prejudicial à família e ao Estado e já desacreditada. No documento de trabalho anteriormente referido $(\mathrm{A} / \mathrm{CONF}$. $87 / 7$ ), catalogou a Secretaria da ONU extenso rol de medidas, igualmente punitivas, que poderiam, com enorme vantagem, substituir a privação da liberdade, para certos delinqüentes. Essa desinstitucionalização, que não pode ser simplesmente importada de outros países, é concebida, basicamente, como parte expressiva de um programa de reforma penal, a ser elaborado segundo critérios que se ajustem à realidade cultural de cada país".

Evidente é, outrossim, que a nossa Reforma Penal encampa essa criteriosa idéia.

Estabelecendo na Parte Geral do Código Penal as penas restritivas de direitos, autônomas, destinadas a substituírem as privativas de liberdade e de três espécies (prestação de serviços à comunidade, interdição temporária de direitos e limitação de fim de semana), prevê, igualmente, no Código de Processo Penal, as medidas alternativas à prisão provisória.

Estas, em enumeração não taxativa, são as seguintes: a) proibição de ausentar-se da comarca, do domicílio ou da residência; b) proibição de freqüentar determinados lugares; $c$ ) obrigação de comparecer às audiências e atos do processo; $d$ ) prestação de assistência material à vitima ou a seus dependentes, se o indiciado ou acusado voluntariamente apresentar proposta neste sentido; $e$ ) obrigação de submeter-se a tratamento médico ou psiquiátrico; $f$ ) interdição provisória de certos direitos; $g$ ) obrigação de prestar determinados serviços não remunerados à comunidade, quando possivel, fora do horário de trabalho normal, se o indiciado ou acusado voluntariamente apresentar proposta nesse sentido; e $h$ ) obrigação de apresentar-se periodicamente ao juiz, em dia e hora por este estabelecidos.

Esclarecido, ainda, que, operando-se a substituição da prisão provisória por qualquer delas (aplicáveis, aliás, também cumulativamente), despiciendo afigura-se enfatizar sua importância e conveniência relativamente à evitação de encarceramento do indiciado ou acusado que dele não necessite para a sua recuperação.

\section{Reprimenda à criminalidade violenta}

Este, mesmo provisoriamente, deve ser destinado aos denominados prisioneiros residuais, em especial criminosos violentos. 
Prevê-se, com efeito, o "fortalecimento do instituto da prisão preventiva com referência ao delinqüente perigoso, nos casos dos crimes de roubo, latrocínio, extorção, seqüestro, estupro, atentado violento ao pudor, rapto não consensual, quadrilha ou bando, e tráfico de entorpecentes ou de substância que determine dependência física ou psíquica" (grifado).

$\mathrm{E}$, da mesma maneira, estabelece-se a prisão temporária, sobretudo para os autores de qualquer das infrações penais apontadas.

Essa nova modalidade de prisão provisória, por sua vez, é introduzida com a finalidade de preencher o espaço vazio que se põe entre a inexistência de prisão em flagrante delito e a inadmissibilidade, dada a falta de concorrência dos respectivos requisitos, de decretação da prisão preventiva.

Sua determinação, uma só vez, é da competência de autoridade judiciária, em conformidade com o disposto no artigo $153, \S 12$, da Constituição Federal (com a redação da Emenda n ${ }^{0}$ 1, de 17 de outubro de 1969), e o prazo, improrrogável, de apenas cinco dias.

Prestando-se, ainda, para a legalização do encarceramento provisório, de sorte a obviar conhecida e corrente prática afrontosa da lei, pelas autoridades policiais, tais vantagens dessa espécie de prisão cautelar foram já patenteadas em meu livro intitulado Persecução penal, prisão e liberdade, São Paulo, 1980, págs. 256/257, no 8 , em que se apresentam, absoluta e necessariamente, reclamantes de urgentes soluções, a saber:

"Por um lado, bem é de ver, não se pode protelar mais a dotação de eficácia maior, considerável, sob qualquer angulação, no combate à criminalidade, principalmente à caracterizada pela violência de certos agentes do ilícito penal.

Por outro, não se violentará, de modo algum, o direito de liberdade do cidadão cuja imaginada ou verificada prática criminosa se esteja apurando, já que permanecerá a garantia de não ser preso senão em flagrante delito ou em razão de ordem escrita de autoridade competente (como, aliás, e corretamente, determinado, a idêntico propósito, no $\S 4^{\circ}$ do art. 99 do Código de Menores - Lei $\mathrm{n}^{\circ}$ 6.697, de 10-10-1979).

Preservada, como de mister, a sua liberdade jurídica, estar-se-á atingindo, também, a finalidade do processo penal, cujo mais relevante dado é a apuração da verdade material; e isto, ao mesmo tempo em que se estará provendo, quando exigível, à garantia da ordem pública, ou à conveniência da instrução criminal ou, ainda, à aplicação da lei penal (cf. art. 312 do CPP, com a redação dada pela Lei $\mathrm{n}^{\circ}$ 5.349, de 3-9-1967)" 
Dúvida alguma pode haver, portanto, segundo me parece, acerca da validade e da utilidade da adoção do instituto da prisão temporária, em nosso novo processo penal.

\section{Procedimento nas causas de competência do Tribunal do Júri}

Arraigado à consciência do nosso povo, o Tribunal do Júri tem competência, definida no artigo 153, § 18, da Carta Magna da República (com a redação da Emenda Constitucional $n^{\circ}$ 1, de 17 de outubro de 1969), para o julgamento dos crimes dolosos contra a vida.

Como antes frisado, dadas as características das causas penais a estes referentes, especial, na expressão da palavra, apresenta-se o respectivo procedimento. E, igualmente, deveras simplificado.

Assim é que, em primeiro lugar, dada a estruturação da denúncia, peculiarizada à proposição do julgamento do acusado pelo Tribunxl do Júri, desnecessária torna-se a mantença do libelo-crime acusatório, por isso suprimido.

Por outro lado, a conformação do ato decisório de saneamento do processo, no sistema procedimental delineado, inclusive com a fixação da classificação legal do fato e do conteúdo da acusação, implica a singeleza da decisão da pronúncia, que prescinde de motivação (exceto se for o caso de revelia ou de outra circunstância determinante da prisão preventiva do acusado).

As regras atinentes ao julgamento também o simplificam no todo, salientando-se a referente à formulação de quesitos, genericamente prescritos para que haja uniformidade de atuação nos mais diferentes rincões do Brasil.

De resto, e para não alongar, ainda mais, esta já demorada exposição, ganha relevo a regionalização do Tribunal do Júri, a ser especificada pela legislação local de organização judiciária e cujas vantagens emergem da simples lembrança da possibilidade maior de julgamento imparcial, por isso mesmo que justo.

\section{Exame criminológico}

Polêmico por excelência, o exame criminológico vê-se deslocado para o seu local apropriado, ou seja, para o processo de execução.

Passa, portanto, a ser regulamentado pela Lei de Execução Penal.

$\mathrm{E}$, com efeito, o momento processual adequado para a verificação dos elementos marcantes da personalidade do infrator da lei penal, como se encontra ela estruturada e qual o modo pelo qual se desenvolve - assim também as razões do comportamento do agente, em confronto com os dados circunstanciais da prática criminosa, - é o correspondente ao da execução da pena privativa de liberdade. 
É que aludido exame somente deve ser admitido após a declaração da culpa ou da periculosidade do acusado, mediante sentença proferida ao final do processo de conhecimento.

$\mathrm{E}$, distinto do exame da personalidade, com o qual guarda relação de espécie a gênero, faz-se obrigatório, obviamente, para os condenados a pena privativa de liberdade em regime fechado, com a determinação de seu enquadramento nas diversas categorias da coletividade penitenciária.

\section{Posicionamento dos sujeitos do processo penal}

Incontroverso é, por outro lado, que a apuração da verdade material constitui dado relevante do precípuo escopo do processo penal, cujo fundamento imediato, como acentuado, é a liberdade jurídica do acusado.

Assim também que tal finalidade só pode ser atingida mediante a tributação de inquisitividade à atuação dos agentes de persecução penal e, especialmente, ao poder direcional do órgão jurisdicional durante o desenrolar da segunda fase desta: a verdade deve ser perseguida incessantemente, de modo que se preserve a liberdade do inocente e se imponha a sanção adequada à infração penal cometida, isto é, à punição merecida pelo culpado (cf. JOSÉ FREDERICO MARQUES, Elementos de Direito Processual Penal cit., vol. I, pág. 130, $\mathrm{n}^{\circ}$ 67; e meu Persecução penal, prisão e liberdade cit., pág. 207, $\mathrm{n}^{\circ} 4, c$ ).

JOAQUIM CANUTO MENDES DE ALMEIDA, Processo penal, ação e jurisdição, São Paulo, 1975, págs. 193/194, nos 74 e 75, explicando a diferença entre o procedimento ex officio, em que se consubstancia o processo penal inquisitório, e a inquisitoriedade ínsita à persecutio criminis (infeliz e correntemente confundidos pela doutrina e pela jurisprudência pátrias. ), veementiza que o nosso "juizo criminal é inquisitório até nas ações exclusivamente privadas"

Realmente, o processo penal moderno delineia-se inquisitório, na sua essencialidade, substancialmente, quer na fase pré-processual, quer na fase pré-processual, quer na da instrução criminal.

Esta, outrossim, para atendimento da necessidade do contraditório indisponivel que a caracteriza (inclusive por força de preceituação constitucional, qual seja a do artigo 153, §16, da Lei das Leis, com a redação da Emenda $n^{\circ} 1$, de 17 de outubro de 1969), realiza-se sob a forma acusatória, assemelhando-se a um processo de partes (cf. JÚLIO B. J. MAIER, La investigación penal preparatória del Ministério Público, Buenos Aires - Córdoba, 1975, págs. 13 e seguintes, $\mathrm{n}^{\circ}$ 1). Vale dizer, na fase da ação penal, o processo faz-se, formalmente, no tocante ao procedimento, acusatório.

Aludida peculiaridade, marcante, reclama, em primeiro lugar, que os órgãos de acusação e de defesa se apresentem como colaboradores 
do agente do Poder Judiciário na perquirição da verdade material. $\mathrm{E}$, noutro aspecto, que, no regime de contradição reciproca determinante de sua atuação, assim que aclarada a realidade o órgão do Ministério Público se poste em consonância com ela, quer pleiteando a absolvição do denunciado, quer apelando de sentença condenatória ou, até, segundo entendimento que tenho propagado, impetrando habeas corpus em favor do indiciado ou acusado.

Isso tudo mostra como distinto do processo civil é o processo penal. Mas não deixa, também, de conotar a necessidade de posicionamento rigorosamente técnico dos sujeitos deste.

Atendendo-a, as Comissões elaboradora e revisora do Anteprojeto do Código de Processo Penal conferem ao órgão jurisdicional o poder de decisão, com exclusividade, como de mister.

Já o Ministério Público, também com exclusividade, e como agente estatal da persecutio criminis, assume a titularidade da ação penal dita pública, abolido que se encontra, de vez, o procedimento de ofício.

$\mathrm{E}$, finalmente, ao cidadão às voltas com a Justiça Criminal confere-se atuação multifária em prol da assecuração de sua liberdade jurídica, tanto no âmbito de ação penal de natureza condenatọ́ria, como pela utilização de ações e medidas tendentes a resguardá-la.

\section{Regulamentação mais expressiva do "habeas corpus"}

Dentre estas, avulta, induvidosamente, o habeas corpus, garantia constitucional mediante a qual se protege a liberdade física do indivíduo (cf. PONTES DE MIRANDA, História e prática do "habeas corpus", $4^{2}$ ed., Rio de Janeiro, 1962 pág. 249, no 1, VICENTE SABINO JÚNIOR, $O$ "habeas corpus" e a liberdade pessoal, São Paulo, 1964, pág. 4, no 1; Constituição Federal, artigo 153, § 20, com a redação dada pela Emenda $n^{\circ}$ 1, de 17 de outubro de 1969).

Tal, aliás, é a sua importância, que se o equipara à própria liberdade que visa a amparar.

Como acentua PONTES DE MIRANDA, in op. et loc. cit.,

"Sem a liberdade de ir, permanecer e vir, não há, nem pode haver, por mais que se sofisme, as demais liberdades. É tipicamente, a liberdade-condição, sem a qual não se podem exercer cargos públicos ou particulares, funções honoríficas ou políticas. 'É o próprio homem, porque é sua vida moral, a base de todo o seu desenvolvimento e perfeição, a condição do gozo de sua inteligência e vontade, o meio de perfazer os seus destinos; e salvaguarda de todos os outros direitos', dizia PIMENTA BUENO.".

Daí a indispensabilidade de alargar os horizontes do habeas corpus, concretizada na legislação projetada, com a especificiação de número 
bem mais alentado de casos de cabimento, como quando, e.g., o cerceamento da liberdade for ordenado ou efetuado sem as formalidades legais ou a sentença não se conformar com a imputação.

Assim também a concessão de liminar, quando a demora no deferimento da ordem puder torná-la ineficaz; o processamento sumaríssimo da impetração e a inclusão de dispositivo, excludente de qualquer dúvida, a respeito da legitimidade do Ministério Público para impetrar habeas corpus em favor de membro da comunhão social.

Tudo, enfim - até mesmo a utilíssima intervenção do Ministério Público no processo de habeas corpus impetrado perante tribunais, alvitrado para que o instituto ganhe a dimensão que a sua expressividade exige da legislação ordinária, complementar da constitucional.

\section{III - CONCLUSÃO}

\section{Derradeiras observações}

Essas são, na mais apertada síntese possivel, as principais informações reclamadas pelo estudo sucinto da relevância processual da Reforma Penal.

$\mathrm{E}$, dado o incontornável alongamento da exposição, penitencio-me com a expressão de VIEIRA, pedindo escusas "por não ter tido tempo de ser breve"

Agradeço, outrossim, a atenção que me foi dispensada pelos distintos ouvintes e fico na expectativa de outra oportunidade em que possamos aqui debater, mais concretamente, os mais importantes aspectos da nova Codificação processual penal brasileira. 